\title{
Turismo e Indicação Geográfica: a denominação de origem da banana da Região de Corupá, Santa Catarina, Brasil
}

\section{Tourism and Geographical Indication: the origin denomination of the banana from Corupá Region, Santa Catarina, Brazil}

\author{
Giseli de Lorena ${ }^{1}$ \\ Patrícia de Oliveira Areas ${ }^{2}$ \\ Felipe Borborema Cunha Lima ${ }^{3}$
}

\begin{abstract}
RESUMO - A comunicação objetiva estabelecer reflexões acerca do processo de Indicação Geográfica (IG) por Denominação de Origem (DO) da banana da Região de Corupá, Santa Catarina, e sua potencialidade para o desenvolvimento sustentável. Iniciado em 2016, obteve o registro em 2018 pelo Instituto Nacional de Propriedade Industrial (INPI). Metodologicamente, o estudo é qualitativo, de natureza exploratória, conduzido via revisão bibliográfica integrativa e documental e com inserção em campo, por meio de observação participante. A escrita do texto segue o debate sobre a importância da IG enquanto fomentadora de arranjos produtivos locais, com ênfase na agricultura familiar e nas relações destes temas com a busca pela proteção das tradições e dos modos de fazer. A principal contribuição da pesquisa foi de fornecer novos dados para correlacionar temas como: indicação geográfica, patrimônio, turismo e gastronomia. Dentre os resultados alcançados está a comprovação da bananicultura na região como uma tradição capaz de garantir a manutenção do saber-fazer, da memória coletiva e a relação de pertencimento entre a população e o município, propiciando a salvaguarda dos costumes. Foi constatado que o processo de DO oportuniza uma redinamização econômica ao propor a interação do turismo e da gastronomia. Estes aspectos ampliam a oferta de novos arranjos produtivos (produtos e serviços) e demonstram a vocação do território para práticas de segmentos turísticos não tradicionais como o comunitário, de experiência e o criativo.
\end{abstract}

Palavras-chave: Turismo. Sustentabilidade. Indicação Geográfica. Bananicultura. Corupá.

\footnotetext{
${ }^{1}$ Mestranda em Patrimônio Cultural e Sociedade (UNIVILLE). Bacharel e Licenciada em História pela Universidade do Contestado (UnC). Licenciada em Geografia pela Universidade Estadual de Ponta Grossa (UEPG). E-mail: giselidelorena@gmail.com

2 Estágio de Pós-doutorado na Universidad de Barcelona (Espanha). Doutora e Mestre em Direito pela Universidade Federal de Santa Catarina (UFSC). Bacharel em Direito pela Universidade Estadual de Maringá (UEM). Doutoranda em Direito pela Universidad de Valéncia (Espanha). Docente do Programa de Doutorado e Mestrado em Patrimônio Cultural e Sociedade da Universidade da Região de Joinville (UNIVILLE). E-mail: patrícia.areas@univille.br

${ }^{3}$ Doutor e Mestre em Turismo e Hotelaria pela Universidade do Vale do Itajaí (UNIVALI). Bacharel em Turismo pela Faculdade de Ciências Sociais Aplicadas (FACISA). Estágio de Pós-doutorado em andamento na Universidade da Região de Joinville - Programa Nacional de Pós-Doutorado (PNPD/CAPES). Docente Colaborador do Programa de Doutorado e Mestrado em Patrimônio Cultural e Sociedade da Universidade da Região de Joinville (UNIVILLE). E-mail: felipebcl2@hotmail.com
} 


\begin{abstract}
The communication aims to establish reflections on the process of Geographical Indication (GI) by Denomination of Origin (DO) of the banana from Corupá Region, Santa Catarina, and its potentiality for the sustainable development. It started in 2016 and it was registered in 2018 by the National Institute of Industrial Property (Instituto Nacional de Propriedade Industrial - INPI). Methodologically, the study is qualitative, exploratory and conducted by an integrative and documentary bibliographic review and with field insertion through participant observation. The writing of the text follows the debate on the importance of GI as promoter of local productive arrangements, with emphasis on family farming and the relationship of these themes searching for the protection of traditions and the ways of doing. The main contribution of the research was to provide new data in order to correlate themes such as: geographical indication, heritage, tourism and gastronomy. Among the results achieved is the proof of the banana cultivation in the region as a tradition able to ensure the maintenance of knowhow, the collective memory and the relationship of belonging between the population and the municipality, providing the customs safeguarding. It was found that the DO process provides an economic revitalization by proposing the interaction of tourism and gastronomy. These aspects expand the offer of new productive arrangements (products and services) and demonstrate the vocation of the territory in practicing non-traditional tourism segments such as community, experience and creative tourism.
\end{abstract}

Keywords: Tourism. Sustainability. Geographical Indication. Banana cultivation. Corupá. 


\section{INTRODUÇÃO}

O município de Corupá, Santa Catarina, SC, apresenta forte relação com a agricultura, principalmente no cultivo das bananas, atividade com aproximadamente 110 anos de tradição na região, apresentando vínculos com o próprio desenvolvimento do município ao longo do tempo. A bananicultura é desenvolvida por meio da agricultura familiar, onde mais de seiscentas famílias vivem da atividade, cultivando em média nove milhões de bananeiras em uma área aproximada de cinco mil e quintos hectares (REBOLAR, 2016). Em 2016 foi solicitado ao Instituto Nacional de Propriedade Industrial (INPI) o reconhecimento da banana da Região de Corupá como "a mais doce do Brasil”, por meio da Indicação Geográfica (IG), na modalidade de Denominação de Origem (DO), o que foi concedido em agosto de 2018 (INPI, 2018).

Se por um lado a repercussão oriunda das Indicações Geográficas (IG) na agricultura não é novidade, estudos mais atuais apontam seu desdobramento e possíveis consequências para outros setores. Vats (2016) afirma que uma IG pode originar efeitos indiretos, e destaca o papel da gastronomia para o turismo. Jimenez, Torre e Rojas (2019) pontuam que a gastronomia vem ganhando maior visibilidade no setor turístico por enfatizar técnicas de preparo, saber-fazer, produtos e estilos de vida de comunidades tradicionais, ou seja, por evidenciar as relações e representações dos aspectos patrimoniais intangíveis. Seal e Piramanayagam (2018) sinalizam que a gastronomia somada aos efeitos das IG pode potencializar a utilização de produtos inovadores e diferenciados resultando na ampliação da experiência turística e consequentemente criar novas demandas e incrementar os benefícios econômicos, socioculturais e ambientais atrelados ao fomento do turismo.

Partindo deste contexto, assume-se como pressuposto norteador desta pesquisa que o processo da IG da banana da Região de Corupá pode se tornar um importante instrumento de potencialização do patrimônio cultural da comunidade local incidindo, portanto, na salvaguarda dos bens. Desse modo, pode se converter em uma ferramenta estratégica para incentivar a organização de novos arranjos produtivos capazes de estimular novas relações nos diversos âmbitos (econômico, social, cultural, ambiental, entre outros). O processo e a obtenção da IG, portanto podem ser utilizados como um instrumento mais equânime na distribuição dos benefícios para a população, a nível 
individual e coletivo e, assim, estimular um desenvolvimento sustentável para o município e para a região.

Nesse sentido, por entender que as IG trazem impactos que ultrapassam o viés econômico e atingem o âmbito social e cultural, busca-se neste artigo refletir e analisar as relações decorrentes deste processo em Corupá e suas possíveis contribuições para o desenvolvimento sustentável do município, por meio da valorização da bananicultura enquanto patrimônio relacionado à memória e à tradição local e seus desdobramentos na promoção de arranjos produtivos, dentre eles o turismo.

A pertinência e a justificativa desta investigação se fazem pela necessidade de ampliar o debate científico sobre as manifestações culturais relacionadas ás práticas gastronômicas, um segmento turístico ainda com pouca visibilidade, sem o devido reconhecimento e como alerta Gimenes-Minasse (2016, p. 14) por vezes "escondido na definição de turismo cultural" ou visto como mero serviço para conferir valor agregado a atrativos e segmentos turísticos tradicionais. A essas questões, soma-se a presença de um elemento distintivo, a Indicação Geográfica, uma característica capaz de conferir um diferencial ao produto, a viabilização de novos arranjos produtivos, dentre eles o turismo e por meio da geração de emprego e renda ampliar as melhorias da qualidade de vida da população.

A seguir será apresentado o referencial teórico de modo a esclarecer os conceitos acionados para a discussão do tema, bem como os respectivos autores. Na sequência são descritos os procedimentos metodológicos adotados na pesquisa para obtenção dos seus resultados provenientes do debate sobre a mobilização de um bem patrimonial, considerado uma tradição da localidade e as implicações que o processo de IG pode acarretar na sua valorização e para o fomento do turismo.

\section{REFERENCIAL TEÓRICO}

Hobsbawn e Ranger (1998), afirmam que a tradição se relaciona com três fatores principais, sendo eles a história, a repetição e a coletividade. A partir disso, os autores apresentam o conceito de tradição inventada, definida como:

um conjunto de práticas, normalmente reguladas por regras tácita ou abertamente aceitas; tais práticas, de natureza ritual ou simbólica, visam inculcar certos valores e normas de comportamento através da repetição, o que 
implica, automaticamente, uma continuidade em relação ao passado. [...] (HOBSBAWN; RANGER, 1998, p. 109).

Segundo os autores citados verifica-se que os costumes se ligam às repetições, que podem ser entendidas como a chave da tradição, juntamente com a história e a coletividade. Portanto, os costumes são importantes para a manutenção das tradições. $\mathrm{O}$ fazer junto, em família e em comunidade, contribui para a manutenção das práticas, que historicamente se fortalecem e se tornam tradicionais, como é o caso da produção de bananas em Corupá.

Esta tradição é importante também para o fortalecimento das relações de identidade entre os membros de determinada comunidade, realçando o pertencimento que é característico do lugar, entendido como uma forma mais restrita do espaço, este mais abrangente. Esta relação de identificação, conforme Tuan (2013), ocorre pelo fato de que com o tempo, acontecimentos simples e do cotidiano, podem se transformar em um profundo sentimento de intimidade para com o lugar. Igualmente, Leite (2007) verifica que os lugares apresentam relações íntimas com os aspectos da vida social, do inconsciente e do passado comum das pessoas.

As relações de identificação e intimidade com o lugar, podem ser ainda maiores, pois conforme Tuan (2013, p. 107), o lar e a cidade natal já são por si só lugares íntimos, ao que o autor conceitua como topofilia, ou seja: “[...]os laços afetivos dos seres humanos com o meio ambiente material". Desse modo, ao analisar as relações que as pessoas constroem com o meio onde vivem se verifica que os sentimentos que se tem para com o lugar são os mais permanentes, sobretudo quando este lugar é o lar e o local onde se ganha a vida.

O agricultor tem para com a natureza uma relação profunda, pois, muito mais do que mera apreciação estética, os recursos naturais simbolizam sua fonte de vida e sobrevivência, estabelecendo uma fusão baseada no apego à terra. Destarte, Tuan (1974, p. 110) afirma que "[...] Os músculos e as cicatrizes testemunham a intimidade física do contato. A topofilia do agricultor está formada desta intimidade física, da dependência material e do fato de que a terra é um repositório de lembranças e mantém a esperança. $[\ldots] "$

Essa identidade cultural, que se relaciona com o lugar, com a memória e com a tradição, é abordada por Meneses (1984) ao explicar que ela se pauta na repetição, reforçando o que já existe, em detrimento do novo. O autor acrescenta que uma identidade 
é formada a partir da semelhança, com si próprio, a partir da condição de vida, tanto psíquica quanto social. Em outros termos, o processo de consolidação do viés cultural de uma identidade ocorre mais facilmente pelo reconhecimento do que pelo conhecimento, isto ocorre em função de uma atitude conservadora que induz o grupo a optar pela adoção de práticas que se alimentam da repetição ao passo que repele o novo, pois este é quase sempre assustador em razão do seu conteúdo desconhecido.

Portanto, se a tradição se alimenta da repetição, ela está intrinsecamente relacionada com a identidade e a busca por manter o já existente. Assim as tradições se perpetuam ao longo do tempo, mantidas, conforme Meneses (1984), pelas memórias individuais ou sociais que cercam este cenário, agindo como suporte fundamental para a identidade cultural de um grupo.

Todavia, Halbwachs (2006) ressalta que não basta apenas o compartilhamento de uma lembrança por um membro do grupo, para que automaticamente todos possam se aproveitar desta memória. Para que a memória coletiva funcione é necessário que existam entre estas pessoas pontos de contanto comuns, que permitam reconstruir as lembranças em conjunto, o que é possível apenas quando se faz parte de um mesmo grupo.

Nesse contexto de valorização dos territórios a partir de suas características não apenas físicas, mas também culturais e históricas vêm alcançando destaque a Indicação Geográfica (IG). Ao longo da história, tanto produtores quanto consumidores foram verificando que os produtos de determinados lugares tinham características diferenciadas, que poderiam ser atribuídas ao local de onde eram provenientes ou mesmo ao modo em que eram feitas (KAKUTA, 2006).

Legalmente, a IG no Brasil é regulada pela Lei nº 9.279, de 14 de maio de 1996, no que tange aos seus artigos 176 a 182 (BRASIL, 1996). De acordo com o artigo 178 da referida lei, a Indicação Geográfica por Denominação de Origem (DO) se define da seguinte forma:

[...] o nome geográfico de país, cidade, região ou localidade de seu território, que designe produto ou serviço cujas qualidades ou características se devam exclusiva ou essencialmente ao meio geográfico, incluídos fatores naturais e humanos (BRASIL, 1996).

Assim, a Lei $n^{\text {o }} 9.279 / 1996$ diferencia as modalidades de Indicação de Procedência (IP) - local conhecido pela produção de um determinado produto ou pela prestação de um serviço - e de Denominação de Origem (DO) - local onde as 
características do produto se devem principalmente às condições naturais e humanas do território (BRASIL, 1996).

Um dos aspectos essenciais para que um processo de IG tenha êxito não apenas para o seu reconhecimento, mas também para que possa ser bem aproveitado após a concessão do registro, é a questão da participação da população em todas as fases. É preciso que haja identificação e vontade popular de que o produto seja de fato reconhecido. Deste modo, o associativismo e a cooperação entre os pequenos produtores, são ingredientes essenciais (NEU; AREAS, 2015). Assim, estas localidades, embora não realizem processos de produção industrializados ou mecanizados, passam a contar com o modo de fazer como diferencial de competitividade no mercado, agregando valor aos seus produtos, que são diferenciados.

Conforme exposto por Niederle (2014), embora tenham surgido como forma de proteção aos produtos de determinadas regiões, atualmente as IG representam alternativas de desenvolvimento para regiões fora do processo da globalização competitiva. Assim, a DO pode ser um instrumento para a valorização dos elementos ambientais, socioculturais e históricos, para além do viés econômico.

Portanto, ao fortalecerem as identidades locais, as IG apresentam-se como uma importante alternativa para reforçar o reconhecimento identitário de determinada localidade. Assim, conforme aponta Castells (1999), se a construção da identidade de um determinado povo está na sua cultura, é fato que, embora o processo de globalização chegue até as localidades, se seu processo produtivo estiver embasado também nas questões culturais, este será sem dúvidas um diferencial.

Jimenéz, Torre e Rojas (2019) corroboram com esta ideia ao descrever os produtos regionais, particularmente os detentores de registros de IG, como um capital cultural e, portanto, dotados da capacidade de fornecer benefícios, nos diversos âmbitos. Nesse sentido, os autores afirmam que a gastronomia enquanto elemento-chave da cultura de um grupo social age como facilitador tanto para a valorização dos traços culturais como na indução de estratégias para o turismo.

No entanto, Neu e Areas (2015) alertam que para as IG atuarem no desenvolvimento é preciso que a comunidade e os integrantes da cadeira produtiva reconheçam a possibilidade de ganhos a partir da cooperação entre todos. Contudo, não pode haver a perda do valor simbólico do patrimônio cultural incutido no produto ou 
serviço ofertado, evitando que ele se transforme em mera mercadoria. Para Lima e Areas (2019), a cultura e o patrimônio cultural são parte da IG, passando a ser também um ativo econômico, que pode ser explorado pelos produtores do território.

Todavia, é necessário tomar cuidado, pois para conquistar ganhos reais advindos dos recursos culturais é necessário que estes sejam utilizados de forma sustentável. Vats (2016) afirmar que uma IG ao ter seu valor cultural associado à atividade turística pode desencadear efeitos múltiplos, pois ao gerar novos arranjos produtivos altera a oferta de empregos e renda, garante a permanência do homem no campo, diminuindo o êxodo rural e as ameaças frente à expansão das áreas urbanas, consequentemente atua na preservação da área rural.

Estes aspectos suscitam que os vínculos entre as IG e os modos de fazer presentes nas comunidades produzem uma interação em que ambas se retroalimentam, isto é, à medida que fortalece o outro também se favorecem. Para tanto, o viés a ser enfatizado nestas IG não pode ser apenas o econômico, pois precisa estar aliado ao desenvolvimento sustentável e ao patrimônio cultural local, sob a pena de que ocorra uma mercantilização da cultura. Isso ocorre porque, conforme aponta Yúdice (2006), a cultura é hoje um recurso que pode atrair investimentos a partir de iniciativas de turismo ou mesmo do setor cultural.

Nesta linha de raciocínio, Neu e Areas (2015) observam que no modelo hegemônico da sociedade capitalista atual para uma IG proporcionar a geração de emprego e renda e conciliar medidas que busquem um desenvolvimento sustentável, fazse necessário manter uma relação direta com o patrimônio cultural. Desta forma resultará, dentre outros efeitos, no fortalecimento de aspectos como a consciência e o pertencimento da comunidade local e o fomento de novos arranjos produtivos e atividades relacionados as culturas locais. Sem embargo Seal e Piramanayagam (2018) constatam que o significado comercial da IG, embora tenha um grande potencial, ainda é pouco explorado em diversos países. Os autores recomendam que os gestores do turismo passem destacar os alimentos locais, principalmente os com registro de IG, buscando promover e divulgar a gastronomia em todos os canais de comunicação possível a fim de ampliar a visão dos turistas e, por conseguinte fortalecer a identidade cultural do lugar e a atividade turística.

Desse modo, pensar nestas questões é fundamental para o campo do patrimônio e para o turismo, uma vez que permite refletir sobre a identidade cultural de um grupo com 
o lugar onde vive e as implicações deste processo. Como Vats (2016) pontua, os efeitos potenciais advindos da IG podem repercutir a nível econômico, ambiental, geração de emprego e renda, de governança, cultural, social e educacional. Lima e Areas (2019) apontam o turismo como um dos pontos de destaque para integrar IG e desenvolvimento, principalmente por permitir associar o segmento do turismo em espaço rural ao viés gastronômico. Esses autores destacam que valorizar os conhecimentos tradicionais e as soluções inovadoras pode incidir no fomento de novos arranjos produtivos, na salvaguarda das tradições e desse modo criar alternativas para ampliar a valorização do patrimônio cultural do município, sem que haja a perda do valor simbólico.

Por outro lado, Frugoli e Bueno (2014) ampliam o entendimento da gastronomia a partir da função social da comensalidade, ou seja, do papel que desenvolve nas relações sociais como vetor de uma dimensão agregadora e de compartilhamento. Nesse sentido o turismo gastronômico viabiliza o intercambio cultural nos diferentes espaços com variados tipos de comércio, produtos e serviços, condição intrínseca a multifuncionalidade e que faculta o fomento de diversos arranjos produtivos dentro da cadeia turística.

Em analogia e este pensamento é possível fazer um paralelo com os estudos de Gimenes-Minasse (2016, p. 7), a qual atribui ao turismo gastronômico a capacidade de criar uma "demarcação simbólica da localidade". Esta atividade quando realizada com produtos certificados ou sob a aura distintiva de uma IG, pode fortalecer a territorialidade, contribuir para a competitividade turística, bem como propor a criação de políticas públicas que visam à salvaguarda das manifestações culturais e a sensibilização dos atores sociais, tanto dos detentores desses patrimônios como dos turistas que fazem uso dos produtos e serviços gerados pela atividade.

Essa interação entre IG, turismo e gastronomia será discutida nas seções seguintes que, mediante os procedimentos metodológicos expostos, trarão as análises da pesquisa sobre o caso da denominação de origem da banana da Região de Corupá, Santa Catarina, por meio de uma síntese dos conhecimentos acionados no marco teórico em contraponto com as experiências dos autores desta investigação visando à apresentação dos resultados mais significativos. 


\section{PROCEDIMENTOS METODOLÓGICOS}

O percurso metodológico utilizado é qualitativo, de natureza exploratória via revisão bibliográfica integrativa. Ele teve como ponto de partida a coleta de dados bibliográficos, envolvendo a seleção, sistematização e leituras de artigos, dissertações e teses coletadas nos bancos de dados, EBSCO, ICAP, Portal de Periódicos CAPES e SCIELO. Esse levantamento teve o intuito de pautar as temáticas deste estudo nas obras clássicas e nas pesquisas mais recentes.

Concomitantemente foi realizada a inserção em campo utilizando-se da observação participante. Embora Correia (2009) afirme que esta técnica possa ser realizada de modo exclusivo, por meio da interação social intensa em experiências e vivências in loco, optou-se pela utilização da análise documental como técnica complementar. Nesse sentido correlacionou-se as atividades ligadas à bananicultura aos documentos da pesquisa, especialmente aos três volumes do pedido de reconhecimento da DO. Tal estratégia permitiu a coleta de novas informações que, após a leitura e transcrição das informações pertinentes, foram registradas no caderno de campo e posteriormente incorporadas ao banco de dados. Para tanto foi utilizado o programa Acess, ferramenta que permite correlacionar as fontes e traçar comparativos por meio de recursos como datas e palavras-chave.

Por fim, ocorreu à construção dos critérios de análise dos dados, optando-se por fazê-la via análise interpretativa de Geertz (2008), que como explicita o autor, requer o detalhamento das fontes, descrição dos resultados em confronto aos autores e marco teórico acionado. Destaca-se também que esta pesquisa está vinculada aos debates de duas investigações em andamento, um projeto de mestrado e um estágio pós-doutoral (PNPD/Capes). Tal fato permitiu iniciar a aplicação das técnicas metodológicas apresentadas, em fevereiro de 2018, bem como oportunizou alimentar o banco de dados continuamente durante todo este processo. 


\section{BANANICULTURA EM CORUPÁ: AGRICULTURA FAMILIAR, MEMÓRIA, TRADIÇÃO E DENOMINAÇÃO DE ORIGEM}

Corupá localiza-se ao norte de Santa Catarina e apresenta população de aproximadamente 16 mil habitantes - estimativa do Instituto Brasileiro de Geografia e Estatística (IBGE), para o ano de 2018 (IBGE, 2019). Essa população está distribuída em uma área de 402.789 quilômetros quadrados, conforme o Instituto Brasileiro de Geografia e Estatística (IBGE, 2019).

Conhecida por suas belezas naturais, tem como um dos principais atrativos as inúmeras cachoeiras, que segundo Rebolar (2016) se entrelaçam com a bananicultura, uma das principais atividades econômicas do município e uma tradição de cerca de cento e dez anos. Lima e Areas (2019) observam que o próprio desenvolvimento do município está relacionado a esta tradição, visto que a mesma teve início logo após a chegada dos primeiros imigrantes alemães na então Colônia Hansa Humboldt, em 1897. Os autores pontuam também que Corupá recebeu este nome apenas em 1944 e somente em 1958 passou a se constituir como município.

Rebolar (2016) indica que estes imigrantes que ali chegaram buscaram desenvolver a agricultura como forma de sobrevivência, mas muitos gêneros agrícolas não se adaptavam ao relevo íngreme e ao clima subtropical, o que levou à opção pela bananeira, cujas primeiras mudas foram trazidas pelos primeiros habitantes não indígenas da colônia, provenientes da atual São Paulo, antiga capitania de São Vicente.

Para evitar desperdícios da fruta, devido à falta de condições adequadas para armazenamento e transporte, com o passar do tempo passou-se a produzir subprodutos a partir da banana, não se limitando apenas à venda da fruta in natura, como banana passa, banana chips, cuca de banana, farinha de biomassa, dentre outros (REBOLAR, 2016).

Além disso, Lima e Areas (2019) apontam que a bananicultura vem sendo aproveitada como ferramenta para estimular o surgimento de outros arranjos produtivos fomentando ainda mais a economia local, como ocorre com a atividade da extração da fibra da bananeira, a qual é vendida e utilizada para a confecção de diversos itens artesanais, tais como flores, objetos de decoração, móveis e biojoias.

Por muito tempo os bananicultores enfrentaram dificuldades quanto à comercialização da fruta. Para minimizar problemas desta natureza, em 1994 foi criada a 
Associação de Bananicultores de Corupá (ASBANCO). O trabalho da Associação não visa apenas auxiliar na comercialização do produto, oferece também capacitações, treinamentos, assistência técnica e desenvolvimento de atividades que promovam a valorização cultural da bananicultura no município (REBOLAR, 2016).

A partir desta trajetória histórica, que ocorreu em paralelo com o desenvolvimento do município, a banana apresenta forte ligação econômica e cultural com Corupá, e por meio da Lei Catarinense $\mathrm{n}^{\mathrm{o}}$ 12.472, de 11 de dezembro de 2002, conquistou o título de Capital Catarinense da Banana (SANTA CATARINA, 2002).

Deste modo, a bananicultura em Corupá é entendida como uma tradição para além das questões econômicas, transportada pelas gerações, vinculada aos costumes e com íntima relação com a cultura local; embora sejam evidenciadas transformações ao decorrer dos anos, não perdeu sua essência. Consequentemente, falar do modo de viver a bananicultura em Corupá é falar do seu patrimônio cultural.

Trazendo as reflexões sobre lugar e topofilia para a análise do caso de Corupá, com um foco na bananicultura, verifica-se que tal atividade representa um lugar, principalmente para aqueles que a exercem. São nestes espaços que a família compartilha dos esforços e dos benefícios do trabalho que exercem na produção das bananas, reforçando a intimidade que tem entre si, com o lar e com a natureza. Assim, a própria materialização da produção contribui para a identidade cultural de Corupá com a bananicultura, seja pela fruta, pelos subprodutos ou ainda pelas ferramentas de trabalho. Indo mais além, objetos como fotografias antigas e documentos também são válidos para este processo.

Por tudo até aqui mencionado, se percebe que mesmo com o avanço das técnicas industriais e da ocupação do espaço de maneira a torná-lo cada vez mais lucrativo, a afetividade e os laços produzidos pelo lugar se tornam maneiras eficazes de manter as tradições e demarcar simbolicamente os espaços. Neste sentido, de acordo com Leite (2007), é relevante observar que as tradições são importantes maneiras de atualizar as relações entre identidade e lugar.

Na bananicultura em Corupá percebe-se que a agricultura familiar é a grande colaboradora para o desenvolvimento de memórias coletivas. O trabalho diário destas pessoas, pertencentes a um mesmo grupo, por vezes, formado por diferentes gerações, propicia trocas que posteriormente poderão evocar memórias de outros, ainda que sob 
percepções distintas. Desse modo a bananicultura e a agricultura familiar agem de forma a manter as tradições, possibilitando que o pequeno agricultor exerça suas atividades contrapondo o ritmo de produção acelerado e a urbanização crescente, ou seja, a atividade repercute a nível local e humano favorecendo um desenvolvimento sustentável.

Nesse contexto, em 2016, deu-se início ao processo de IG, por DO, para a banana da Região de Corupá (envolvendo os municípios de Corupá, São Bento do Sul, Jaraguá do Sul e Schroeder) como "a mais doce do Brasil". O pedido do registro teve como suporte diversos estudos técnicos para compreender os impactos provenientes das condições geográficas da região, do modo de produção e dos fatores físico-químicos da fruta em relação ao seu sabor, decorrente do clima subtropical da região, que faz a fruta demorar mais para se desenvolver, causando o acúmulo de potássio na banana, tornandoa mais doce (SILVA, 2016). No ano de 2018, mais especificamente em 28 de agosto de 2018, foi concedido o Registro da DO, "Banana da Região de Corupá”, pelo Instituto Nacional de Propriedade Industrial (INPI, 2018).

Em Corupá, a bananicultura já movimenta a economia e a cultura, podendo ser considerada símbolo do município. Tanto a produção da fruta quanto dos subprodutos da banana fomenta a renda da população, direta ou indiretamente. Além disso, as atividades desenvolvidas pela ASBANCO também apresentam importância neste processo, ao fortalecer o associativismo e a identidade cultural dos produtores, características estas tão importantes para o sucesso das IG.

Neste sentido, Lima e Areas (2019), afirmam que o pedido do reconhecimento da DO para as bananas de Corupá, surgiu a partir da correlação entre história, tradição, saberfazer e a busca por uma alternativa de desenvolvimento a partir da autenticidade natural e cultural do cultivo do produto. Deste modo, se fortalecidas estas relações, a DO da "banana mais doce do Brasil" pode ser fator importante para a sustentabilidade do município e a permanência da tradição da bananicultura.

Lima e Areas (2019) apontam ainda que a Denominação de Origem "banana mais doce do Brasil” traz a possibilidade de relacionar a produção agrícola a novas relações como o turismo no município, visto que algumas atividades realizadas no território corupaense convergem diretamente com a bananicultura. Um exemplo é a festa do dia da banana, comemorado anualmente no município, no dia 21 de agosto. 
Ao analisar os cartazes do evento e nas mídias da ASBANCO se constata a ampliação da festividade. A edição de 2018 ocorreu entre os dias 08 a 21 de agosto, contando com diversas atividades, tais como: palestras nas escolas municipais, desfile de máquinas e entidades, escolha das musas da banana, exposições, feira de artesanato e subprodutos, concurso da melhor cuca de banana, apresentações culturais e o festival gastronômico, no qual é possível provar dentre outros pratos, o "x banana com bacon". De acordo com Lima e Areas (2019), a gastronomia vem se tornando uma importante ferramenta de valorização dos traços culturais da localidade, em especial dos ativos provenientes da bananicultura, atuando de modo a ressaltar o pertencimento da comunidade por meio do orgulho, da memória e da identidade. Para os referidos autores, esta prática fomenta novas iniciativas, dentre elas as experiências turísticas e culturais sob o recorte gastronômico baseado nos aspectos da ruralidade.

Outro evento que ganha destaque no calendário do município, para Lima e Areas (2019) é o Bananalama, realizado anualmente desde 2004, sendo reconhecido pelo Guiness Book como o maior encontro de trilheiros do mundo. A trilha pode ser realizada de moto ou de quadriciclo, o trajeto realizado pelos participantes percorre desde a área urbana até parte dos bananais na área rural. A presença da banana e dos produtos dela derivados é um atrativo para os visitantes ao longo do encontro, que geralmente ocorre no mês de julho, movimentando o comércio local.

Tais aspectos sinalizam que o entrecruzamento da bananicultura e do turismo faculta, portanto, a construção de um processo de desenvolvimento rural para Corupá baseado na multifuncionalidade territorial. Faz-se necessário pontuar que nesta pesquisa assume-se o entendimento de multifuncionalidade na ótica de Covas (2007), ou seja, como resultado da diversificação da base e dos bens privados e públicos, passível de produzir melhorias ao espaço e aos indivíduos.

Nessa acepção, esta pesquisa reafirma o pensamento de Lima e Areas (2019), que ecoturismo, banana, cultura e culinária são palavras-chave do turismo para Corupá, bem como o entendimento de que a IG pode estimular significativas colaborações, ao valorizar os produtos locais, fortalecendo os laços entre comunidade e produtores, aumentando a lucratividade do município e potencializando arranjos produtivos locais que poderá refletir na qualidade de vida e bem-estar da população. 
Outrossim, é pertinente observar que as análises que se constroem nesta investigação, corroboram que a relação entre IG, turismo e gastronomia em Corupá sejam alinhadas com as ideias apresentadas por Silva, Cunha-Lima e Farias (2018), ou seja, planejado sob o viés de um contexto solidário e dentro de perspectivas éticas, a exemplo do turismo comunitário, ou iniciativas que busquem o desenvolvimento dos territórios de forma ética e da valorização cultural.

Desse modo o fortalecimento das identidades e das tradições locais ampliam as alternativas a serem aplicadas nas futuras intervenções turísticas em Corupá. Como demonstrado nas reflexões de Silva, Cunha-Lima e Christoffoli (2016), sobre formatos turísticos que buscam novos formatos em contraponto ao modelo turístico tradicional, por meio do engajamento de atores sociais aptos a compartilhar seu modo de vida e seu patrimônio, seja ele cultural ou natural, ao mesmo tempo em que mantêm as suas atividades econômicas, oportuniza um distanciamento do turismo rural convencional e aproxima a atividade do formato comunitário.

Por fim, é possível entender que a denominação de origem "banana mais doce do Brasil" auxilia no fomento do turismo de Corupá, com vistas a entender a relação entre o processo, à conquista da DO e a valorização das potencialidades locais. A DO favorece não apenas a economia do município, mas também a transformação social, ambiental e cultural, por meio da democratização dos ganhos advindos com estas atividades e, portanto, impactando de forma positiva na qualidade de vida da população.

\section{CONSIDERAÇÕES FINAIS}

A bananicultura é uma atividade tradicional no município de Corupá, o qual teve início com os imigrantes e se manteve ao longo do tempo, por meio da agricultura familiar, apesar das condições físicas desfavoráveis, tais como o relevo íngreme e o clima subtropical. As relações entre memória e identidade, que permeiam a bananicultura corupaense, contribuíram para a permanência da atividade, ao ponto de-que se tornasse uma tradição no município, passada de geração em geração.

Em de 2016 se deu início o processo de obtenção do registro da IG do tipo DO para a banana da Região de Corupá como "a mais doce do Brasil”, alicerçado nos estudos que apontaram a capacidade de determinadas características físicas do território em 
influenciar o processo de desenvolvimento e maturação da fruta, resultando em um maior acumulo de potássio o tornando-a mais doce. Em 2018, o INPI aprovou o pedido e concedeu a DO pautado na relação histórica de Corupá com a produção de banana e nas implicações provenientes das características do território.

A pesquisa comprova que a tradição da bananicultura garante sua continuidade por meio da manutenção do saber-fazer, da memória coletiva da população, da relação de pertencimento que se cria entre a comunidade e o lugar, além da salvaguarda dos costumes, mantidos ao longo do tempo. Desse modo, mantendo a tradição viva, este conjunto de fatores consolida a bananicultura no município, a qual pode ser fortalecida com a recente conquista do registro de "banana mais doce do Brasil", por meio da DO, proporcionando mudanças positivas no local.

Assim, diante da produção de bananas em Corupá e a gama de subprodutos que se desencadeiam a partir da fruta, a DO pode corroborar para um desenvolvimento econômico ainda maior, tendo no associativismo um importante pilar de apoio para a organização e planejamento das atividades a serem desenvolvidas pelo setor produtivo. Todavia, estas questões econômicas precisam estar aliadas às questões socioculturais, pois é fato que apenas a obtenção do registro de DO não significa sucesso imediato. É necessário um trabalho contínuo para reforçar os laços da comunidade com a atividade desenvolvida, o que se faz a partir da memória, da identidade e da tradição, que representam a chave para este processo. Tudo isso aliado à inovação pode agregar valor à atividade da bananicultura, permitindo o surgimento de novos arranjos produtivos no local, como por exemplo, o turismo.

Neste processo o turismo se revela como uma potencialidade capaz de fortalecer estas ferramentas e proporcionar melhorias à qualidade de vida da população. Considerando a vocação do território e a presença de grupos e associações, o fomento do turismo comunitário pode ser uma alternativa ao oferecer mais que atividades contemplativas aos turistas, como também vivências e experiências. Dessa forma, diversos segmentos podem ser desenvolvidos concomitantemente tais como o rural, o criativo, o de experiência, entre outros, aproximando turistas e moradores a partir das atividades cotidianas relacionadas à cultura local, em especial a banana e seus subprodutos, além dos elementos ambientais. Estas iniciativas podem promover novos conhecimentos aos turistas, e complementar a renda dos agricultores. 
Ao corroborar com esta perspectiva a pesquisa detectou que a diversidade de atrativos e a abrangência de manifestações culturais na localidade, associados a agricultura, gastronomia, natureza, saberes-fazer, entre outros elementos alicerçados na tradição, favorece a reflexão de que seja mais viável então adotar o desenvolvimento de projetos que enquadrem a atividade turística de Corupá como uma proposta de turismo em espaço rural, pois este não estaria resumido às características do turismo rural, que é condicionado a manter uma estrita relação com o ambiente rural.

Em virtude do processo da DO da banana da Região de Corupá ser recente os estudos voltados a este registro são insipientes e configuram a maior limitação da pesquisa. No entanto este fato também é a principal contribuição da investigação, ou seja, fornecer novos dados que correlacionem temas como indicação geográfica, bananicultura, patrimônio, turismo e desenvolvimento. Desse modo, esse artigo produz conhecimento aplicável para os agricultores e gestores deste processo. Nesse sentido indica-se como propostas de investigação futura a ampliação desta pesquisa para os demais municípios que compõem a Região de Corupá.

\section{REFERÊNCIAS}

BRASIL. Lei no 9.279, de 14 de maio de 1996. Disponível em:

$<$ http://www.planalto.gov.br/ccivil_03/Leis/L9279.htm>. Acesso em: 12 nov. 2018.

CASTELLS, M. O poder da identidade. São Paulo: Paz e Terra, 1999.

CORREIA, M. C. B. A observação participante enquanto técnica de investigação.

Pensar Enfermagem. v. 13 n. 2, p. 30-36, 2009.

COVAS, A. M. A. Ruralidades (II) - agricultura multifuncional e desenvolvimento rural. Faro, Portugal: Edições da Universidade do Algarve, 2007.

FRUGOLI, R.; BUENO, M. S. O Círio de Nazaré (Pará, Brasil): relações entre o sagrado e o profano. Turismo e Sociedade, v. 7, n. 1, p. 135-155, jan./mar. 2014.

GIMENES-MINASSE, M. H. S. G. Notas sobre políticas públicas a respeito da gastronomia no contexto turístico brasileiro. Turismo e Sociedade, v. 9, n. 3, p. 1-18, set./dez. 2016.

GEERTZ, C. A interpretação das culturas. Rio de Janeiro: LTC, 2008.

HALBWACHS, M. A memória coletiva. São Paulo: Centauro, 2006. 
HOBSBAWN, E.; RANGER, T. A invenção das tradições. 2. ed. São Paulo: Paz e Terra, 1998.

INSTITUTO BRASILEIRO DE GEOGRAFIA E ESTATÍSTICA (IBGE). Brasil, Santa Catarina, Corupá: Panorama, 2019. Disponível em:

$<$ https://cidades.ibge.gov.br/brasil/sc/corupa/panorama> Acesso em: 04 jul. 2019.

INSTITUTO NACIONAL DA PROPRIEDADE INDUSTRIAL (INPI). Indicações Geográficas: Seção IV. Revista da Propriedade Industrial, n. 2486, 2018. Disponível em: $<$ http://revistas.inpi.gov.br/pdf/Indicacoes_Geograficas2486.pdf $>$. Acesso em: 30 ago. 2018.

JIMENÉZ, J; A. C.; TORRE, M. G. M. V.; ROJAS, R. H. Analysis of the Tourism Demand for Iberian Ham Routes in Andalusia (Southern Spain): Tourist Profile. Sustainability. v. 11, n.16, p. 1-21, 2019.

KAKUTA, S. M. Indicações geográficas: guia de respostas. Porto Alegre: SEBRAE/RS, 2006.

LEITE, R. P. Contra-usos da cidade: lugares e espaço público na experiência urbana contemporânea. 2. ed. São Paulo: Unicamp, 2007.

LIMA, F. B. C.; AREAS, P. de O. O processo de Denominação de Origem da Banana de Corupá - SC como experiência turístico-cultural. In: LAVADOSKI, J.;

BRAMBILlA, A.; VANZELA, E. (Org). Alimentação e Turismo: oferta e segmentos turísticos. João Pessoa: Editora do CCTA, 2019.

MASHABI, R.; MASHABI, N. Tourism Development Based on Local Culture in Segaran Village, Karawang, West Java. In: 3RD UNJ INTERNATIONAL CONFERENCE ON TECHNICAL AND VOCATIONAL EDUCATION AND TRAINING. Anais... KnE Social Science, 2018. p. 32-38.

MENESES, U. B. de. Identidade cultural e arqueologia. Revista do Patrimônio Histórico e Artístico Nacional, n. 20, p. 33-36, 1984.

NEU, M. F.; AREAS, P. de O. O patrimônio cultural como ativo territorial no desenvolvimento regional. In: DALLABRIDA, V. R. Indicação geográfica e desenvolvimento territorial: reflexões sobre o tema e potencialidade no estado de Santa Catarina. São Paulo: LiberArs, 2015.

NIEDERLE, P. A. Desenvolvimento, instituições e mercados agroalimentares: os usos das Indicações Geográficas. In: DALLABRIDA, V. R. Desenvolvimento territorial: políticas públicas brasileiras, experiências internacionais e a Indicação Geográfica como referência. São Paulo: LiberArs, 2014.

REBOLAR, P. B. M. Banana da Região de Corupá: Levantamento histórico e cultural. Florianópolis: SEBRAE, 2016. 
SANTA CATARINA. Lei Ordinária n 12.472, de 11 de dezembro de 2002.

Disponível em: $<$ http://leisestaduais.com.br/sc/lei-ordinaria-n-12472-2002-santacatarina-reconhece-o-municipio-de-corupa-como-capital-catarinense-da-banana-201510-08-versao-compilada>. Acesso em: 5 jun. 2018.

SILVA, A. L. da. Banana da Região de Corupá: Dossiê Técnico-Científico. Florianópolis: SEBRAE, 2016.

SILVA, Y. F.; CUNHA-LIMA, F. B.; FARIAS, I. S. Feira de Alimentos: espaço de memória e desenvolvimento local no Algarve. Revista Turismo y Desarollo Local, v. 11, n. 25, p. 01-18, dez. 2018.

SILVA, Y. F.; CUNHA-LIMA, F. B.; CHRISTOFFOLI, A. R. Turismo rural comunitário: gestión familiar y estrategias de consolidación em el Estado de Santa Catarina (Brasil). Estudios y Perspectivas em Turismo, v. 25, p. 576-596, 2016.

SEAL, P. P.; PIRAMANAYAGAM, S. Branding geographical indication (GI) of food and its implications on gastronomic tourism: an indian perspective. In: ADVANCES IN HOSPITALITY AND TOURISM MARKETING AND MANAGEMENT CONFERENCE, 2018. Anais... Bangkok Thailand, 2018. p. 123-130.

TUAN, Y. Espaço e lugar: a perspectiva da experiência. Londrina: Eduel, 2013.

Topofilia: um estudo da percepção, atitudes e valores do meio ambiente. São Paulo: Difel, 1974.

VATS, Naresh Kumar. Geographical Indication - the factor of rural development and strengthening economy. Journal of Intellectual Propriety Rights. v. 21, p. 347-354, set./nov. 2016.

YÚDICE, G. A conveniência da cultura: usos da cultura na era global. Belo Horizonte: Editora UFMG, 2004.

Recebido em: 08-07-2019.

Aprovado em: 30-11-2019.

Versão aprovada para publicação em: 16-12-2019. 